\title{
Student views of using e-learning tools to facilitate independent learning of anatomy and physiology
}

\section{Fiona Roberts}

Robert Gordon University, UK

\section{Abstract}

The ability to undertake life-long learning is essential in the world today and this requires independent learning skills. A growing body of evidence suggests integration of computer assisted learning could potentially replace face-to-face teaching entirely with no detriment to students. Case study methodology was therefore utilised to investigate students' perceptions of the use of online resources to replace face-to-face teaching and the impact of this approach on student outcomes when learning anatomy and physiology. Concurrent mixed methods, incorporating pragmatic comparison of summative assessment scores with a questionnaire gathering student opinion of this learning method, were used. Students had access to typical Anatomy and Physiology Computer Aided Learning resources. Additional adaptive learning activities $(A L A)$ and homework quizzes were provided. Directed study was given for every topic. All but four topics were supported by interactive workshops; these four were supported by additional ALA and an optional 'drop in' session.

The results indicated no difference in student outcome for topics taught with and without workshop support. However, although students understood the rationale for the change and sufficient guidance was given, they found the independent learning challenging due to lack of intrinsic motivation and confidence. Engagement with ALA and homework quizzes was limited.

Students do not want more independent learning and like the confidence provided by attending workshops. Using more selective online resources may be beneficial and ensuring that materials addressed online are used in other classes may be a way forwards, thus ensuring a constructivist approach to learning while encouraging more independent learning. 
Keywords: Computer Aided Learning; adaptive learning activities; constructivist learning; motivation; perceptions.

\section{Introduction}

In 2007 the European Community (2007) recommended that individuals must achieve key knowledge, skills and attitudinal competencies appropriate to their context if they are to be successful in the world today. They indicated that fundamental to this is learning to learn to enable life-long learning, a requirement of many professional regulatory bodies (HCPC, 2011; GMC, 2012; NMC, 2015) to ensure continuing professional development and competency to practice. This suggests that during university-based foundation training, health professional students must develop strong skills in learning to learn.

Learning opportunities must enable students to actively engage in the learning process, thus enabling deeper learning (Freeman et al., 2014). Anatomy and Physiology (A \& P) teaching has traditionally been lecture-based, yet evidence has shown that attention levels fluctuate throughout lecture periods (Bunce et al., 2010) - superficial learning is encouraged as is dependence on others for the acquisition of knowledge (Bligh, 2000). Consequently learning to learn is not facilitated.

In recent years the School of Health Sciences, Robert Gordon University, Aberdeen, Scotland, has taken a more active approach to help students learn A \& $P$, a foundation area of knowledge for all our professions. Students have been provided with directed reading to complete before attendance at a workshop on each of the A \& P topics. During workshops students actively engage in activities that clarify and consolidate directed study, with the aim of helping students gain real meaning about how the body is structured and functions: a constructivist approach to learning (Fry et al., 2014) that utilises principles of Andragogy (Taylor and Laros, 2014), aiming at deeper learning. Examples of activities are acting out physiological processes and building accurate, functional representations of body parts from craft materials. This delivery method has seen an improvement in module outcomes, with the student failure rate in the assessment reducing from approximately $8 / 140$ to $2 / 140$ students per year. 
The integration of computer assisted learning $(C A L)$ with face-to-face teaching has been reported to have a positive impact on student learning (Elizondo-Omana et al., 2004; Gopal et al., 2010; Faleye, 2011) with the following specific benefits reported:

- Improved retention of information (Gopal et al., 2010).

- Repeated access enables more gradual assimilation of knowledge (Coffee and Hillier, 2008).

- Deeper learning (Mayer, 2003).

- Improved understanding of three-dimensional structures and their function and relationships (Hilbelink, 2009).

- Flexible access to learning to suit the student and therefore encouragement of a student-centred approach to learning (Coffee and Hillier, 2008).

- Greater interaction in class when online revision has been undertaken in advance (Raynor and Iggulden, 2008).

In some areas of nursing and physiotherapy, for example, CAL has progressed to replace face-to-face teaching with no detriment to student achievement (Castilho-Weinert and Lopes, 2009; Bloomfield et al., 2010). This may facilitate the development of an independent approach to learning as desired by the European Parliament and professional regulatory bodies.

Consequently, the A \& P team in the School of Health Sciences proposed to investigate student perceptions of a more independent way of learning A \& P using e-learning resources. The impact on student achievement would also be investigated since any enhancement must not be detrimental to student outcomes and should improve outcomes.

\section{Method}

A concurrent mixed methods case study methodology was utilised. The focus was on allowing all students the opportunity to provide their views of the new learning method: achievable via individual interview, focus group or questionnaire. However, strong individuals could influence the reliability of data collected in a focus group (Sparks and Smith, 2014), while students may feel inhibited by the direct and personal nature of an 
interview (Cohen et al., 2000). Additionally both focus groups and interviews would have been time and labour intensive while producing a potentially overwhelming amount of data. Consequently, although depth of information is sacrificed when questionnaires are used, this was the preferred method of data collection (Cohen et al., 2000). Students could anonymously give their opinions and the quantity of information would be manageable.

The focus of enhancement is to not, however, focus solely on the student experience. It also aims to improve outcomes for students (QAA, no date) which necessitates comparison of grades to show the impact, if any, of the enhancement. Although student cohorts differ year on year, similar trends in student achievement have been identified in the A \& P module: average grades for each subject group have been similar each year and consequently a retrospective comparison of student grades was utilised.

The A \& P module is delivered to all students in year 1 (Scottish Credit and Qualifications Framework (SCQF) level 7)(SCQF, no date) of the BSc (Hons) Applied Sports and Exercise Science (ASES), Diagnostic Radiography (DR), Occupational Therapy (OT) and Physiotherapy (PT) courses in the School of Health Sciences. The module is delivered over the first 12 weeks of year 1 and, since 2011, has utilised interactive workshops for which the students are required to prepare directed study.

Consultation with the School Ethics Review group indicated that ethical approval was not required as this project was considered a service evaluation. Students were advised that new resources were being evaluated with a view to establishing if they could reshape module delivery and facilitate their learning. Consequently their views of these, and the drop in sessions that would replace some workshops, were important to inform future module delivery. They were assured of confidentiality relating to any data utilised in any reports or publications.

\section{Recruitment}

All 155 students undertaking A \& $\mathrm{P}$ took part in the project as this was the only way the module was delivered. This also avoided contamination of results from friends sharing resources if they were in different arms of a study. 


\section{Learning materials}

A review of possible core texts and supporting online resources was undertaken for 2013 delivery. Anatomy and physiology textbooks are all very similar in content but level of detail differs. Online resources are also very similar but one resource incorporated adaptive learning activities (ALA). ALA establishes what each student knows and does not know, and adjusts the learning content provided to each individual based on this (Griff and Matter, 2013). It was considered that this had the potential to enable students to learn the required material independently and that it may suit some individuals' learning styles, for example, those who prefer to learn visually and/or on their own. Consequently a change in textbook and online resources was implemented to allow incorporation of ALA. The usual online resources of podcasts, quizzes, animations and cadaver dissection were available and enabled students to choose their preferred learning tools dependent on their preferred learning styles (Al-Qahtani and Higgins, 2013).

\section{Module delivery}

An introduction to the ethos of independent learning has been part of the module since 2011. This interactive lecture emphasises that the whole module is delivered without lectures to encourage independent but guided active learning. Students were informed that new and extensive online resources were being trialled. This was to establish their ability to facilitate student learning and help the development of independent learning skills.

For every topic a directed study sheet was available to students via the virtual learning environment. This detailed the required reading in addition to the animations and videos to be reviewed for the topic prior to class. ALA to complete before class, and homework quizzes to complete after, were introduced for 2013. As with previous years a 'what you need to know sheet' was available to enable students to check if they had learnt the necessary content for each topic. A workshop was provided to support student learning and required students to undertake different activities, utilising their directed study, to help them understand the content more clearly with the aim of achieving deeper learning. Students were required to attend these sessions but only one course (Applied Sport and Exercise Science) actually had an attendance requirement. 
Four of the 18 topics were randomly selected to have a greater focus on independent learning supported by e-learning resources. Two anatomy and two physiology topics were selected from topics placed in a hat. Directed study sheets and 'what you need to know' sheets were also provided for these topics. However, there was a greater focus in the directed study to ALA and online resources. These four topics (skeleton bones and joints; cardiovascular system; respiratory system; and the knee) were supported by a 'drop in' session where staff could answer questions and provide clarification about any areas individuals were struggling with relating to the topic. These were entirely optional for all students. Responsibility for undertaking learning, checking understanding and accessing support was firmly placed with the students.

Students were guided to find the various online resources in a class session held in a computer room. They were also provided with a document detailing the different resources. This document provided written descriptions of each resource and directions on how to access them, supported by 'screen dumps' to aid online navigation. Although not mandatory, students were strongly advised to complete homework quizzes and ALA to monitor their own progress and to facilitate their learning.

Although 18 topics were taught, only 16 were included in the summative examination. The two initial topics (cells and tissues and terminology) were incorporated into other topics.

\section{Outcome measures}

Scores for each homework quiz were gathered along with data on each student's interaction with the ALA. Summative assessment results were also collated for comparison with 2012 and 2013 results (the two previous cohorts who had undertaken the module with the directed study focus). Comparison with these cohorts was thought to enable greater consideration of the possible impact of individual cohort differences on results.

A questionnaire was developed to gather student views of the different resources they had access to and the use of 'drop-in' sessions. A copy of the questionnaire is provided in Appendix 1. The questionnaire asked about the student views on the usefulness of the various online resources through use of a Likert scale. Opportunity for qualitative 
comment via open questions was also provided relating to the 'drop-in' sessions. The questionnaire was piloted with three students undertaking the module as an admission requirement for another course. Feedback indicated minor amendments were required which were undertaken. Students were asked to complete the questionnaire after they had submitted their mock exam attempt. This meant that they were not influenced by summative assessment scores but the recent teaching, and therefore their views would be current and less influenced by memory, which could be altered through discussion with others.

\section{Data analysis}

Descriptive analysis of data from the questionnaire, and thematic analysis of questions providing qualitative data relating to student perceptions, was undertaken. Summative assessment results were analysed using SPSS V21. Comparison of summative assessment scores of cohorts from 2011/12, 2012/13 and 2013/14 was undertaken. After testing for normality of distribution, ANOVA and post hoc analysis using Bonferroni's test was completed. Analysis by subject group across the three years, and a comparison of student achievement in topics taught with and without workshops, was also undertaken. Statistical significance was considered if $p<0.05$. Data regarding student engagement with homework (HW) and ALA was collated from excel spread sheets and included homework scores and ALA attempts.

\section{Results}

155 students undertook the module with 146 students submitting questionnaires. Questionnaire completion was variable across questions however. Only 55\% completed the question about the frequency of use of the various resources and results are shown in Table 1, with their perception of the usefulness of the various resources reported in Table 2. 
Table 1. Self-reported use of e-learning tools (percentages reported).

\begin{tabular}{|l|l|l|l|l|}
\hline Resource & $\begin{array}{l}\text { Once/week or } \\
\text { less }\end{array}$ & $\begin{array}{l}\text { Twice/week or } \\
\text { more }\end{array}$ & Never & $\begin{array}{l}\text { Not } \\
\text { completed }\end{array}$ \\
\hline Dissection tool & 27 & 6 & 15 & 46 \\
\hline Dissection quiz & 24 & 15 & 10 & 52 \\
\hline $\begin{array}{l}\text { Dissection } \\
\text { animations }\end{array}$ & 32 & 4 & 8 & 57 \\
\hline ALA & 13 & 38 & 1 & 45 \\
\hline $\begin{array}{l}\text { Other } \\
\text { animations }\end{array}$ & 27 & 2 & 21 & 49 \\
\hline Pod casts & 12 & 3 & 38 & 47 \\
\hline Other resources & 11 & 6 & 34 & 49 \\
\hline
\end{tabular}

Qualitative responses to why resources were not used indicated that students most often did not use the podcasts, other learning resources and dissection quiz because they did not know they were there or could not find them. Students also commented that they were deterred from using the animations and podcasts as they did not like the voice on the audio.

Table 2. Perceived usefulness of e-learning tools (percentage).

\begin{tabular}{|l|l|l|l|l|}
\hline & $\begin{array}{l}\text { Poor } \\
1-2\end{array}$ & 3 & $\begin{array}{l}\text { Good } \\
4-5\end{array}$ & $\begin{array}{l}\text { Not } \\
\text { completed }\end{array}$ \\
\hline Dissection tool & 12 & 16 & 50 & 21 \\
\hline Dissection quiz & 7 & 23 & 41 & 32 \\
\hline Dissection animations & 8 & 27 & 34 & 31 \\
\hline ALA & 4 & 12 & 78 & 6 \\
\hline Homework quiz & 5 & 21 & 64 & 10 \\
\hline Other animations & 14 & 15 & 13 & 58 \\
\hline podcasts & 11 & 7 & 6 & 75 \\
\hline $\begin{array}{l}\text { Other learning resources - crosswords, } \\
\text { labelling exercises, flashcards }\end{array}$ & 7 & 14 & 11 & 67 \\
\hline
\end{tabular}


Responses to the questions relating to the independent learning style are shown in Table 3. All students responded to these statements and the numbers by subject group are: ASES 47, DR 26, OT 34 and PT 38. They indicate ASES and OT students found it difficult to adjust to the independent learning required but sufficient guidance was provided. Students also appear to have found the homework quizzes useful (Table 3 vii and viii). Qualitative comments gathered from the open question asking for student views on the more independent learning required form four main themes: depth of knowledge gained from the topic (18 comments), autonomy of the learning process (13 comments), confidence in their own learning (10 comments), and motivation to learn (28 comments). Typical examples of comments relating to each of these themes are provided in Box 1.

\section{Box 1. Examples of comments made by students.}

\section{Depth of knowledge}

- I felt I didn't have as good a depth of knowledge nor did I retain it for as long a time period.

- Was easy enough to note take but not as well remembered.

\section{Autonomy of learning process}

- I didn't like not having the tutorial because the tutorial helped me learn the topic so when there was a drop-in I never went but not because I didn't have any questions. I had too many and too much I didn't understand so wouldn't know where to start asking.

- $\quad$ They were harder to learn because you were completely on your own without anyone going over the topics with you.

- $\quad$...if they [drop-ins] became mandatory then I think I would have benefitted a lot more from doing more classes with a teacher.

- I understand that it is productive learning - however far too little guidance and independent study - felt a bit drowned and unsupported.

\section{Confidence in own learning}

- Less confidence in knowing content but learning experience and outcome was similar to other topics. 


\section{Motivation to learn}

- $\quad$ The drop ins were not a good idea because there was no motivation to go to them and I didn't. they should be mandatory. DR student

- $\quad$ Because they sessions were optional it was very difficult to find the motivation to come in when we have our online resources at home. I suppose they could be useful for any major questions but I did not have any.

Table 3. Questions relating to independent learning style.

\begin{tabular}{|c|c|c|c|c|c|}
\hline & & & Agree & $\begin{array}{l}\text { Don't } \\
\text { know }\end{array}$ & Disagree \\
\hline \multirow[t]{4}{*}{ i } & \multirow{4}{*}{$\begin{array}{l}\text { I found it difficult to get to grips with the } \\
\text { independent learning style used }\end{array}$} & ASES & 59 & 8 & 32 \\
\hline & & DR & 35 & 8 & 58 \\
\hline & & OT & 68 & 6 & 26 \\
\hline & & $\mathrm{PT}$ & 31 & 15 & 54 \\
\hline \multirow[t]{4}{*}{ ii } & \multirow{4}{*}{$\begin{array}{l}\text { I understood why the independent learning } \\
\text { style was used }\end{array}$} & ASES & 72 & 21 & 7 \\
\hline & & DR & 92 & 4 & 4 \\
\hline & & OT & 91 & 9 & 0 \\
\hline & & PT & 97 & 3 & 0 \\
\hline \multirow[t]{4}{*}{ iii } & \multirow{4}{*}{$\begin{array}{l}\text { Insufficient direction was given to what I } \\
\text { needed to learn }\end{array}$} & ASES & 19 & 19 & 62 \\
\hline & & DR & 15 & 15 & 70 \\
\hline & & OT & 15 & 3 & 82 \\
\hline & & PT & 16.5 & 16.5 & 69 \\
\hline \multirow[t]{4}{*}{ iv } & \multirow{4}{*}{$\begin{array}{l}\text { It was more difficult to learn the topics not } \\
\text { supported with workshops }\end{array}$} & ASES & 62 & 8 & 30 \\
\hline & & DR & 42 & 15 & 42 \\
\hline & & OT & 76 & 9 & 15 \\
\hline & & $\mathrm{PT}$ & 59 & 8 & 33 \\
\hline \multirow[t]{4}{*}{$\mathrm{v}$} & \multirow[t]{4}{*}{ ALA helped me learn more topics } & ASES & 70 & 19 & 11 \\
\hline & & DR & 81 & 7 & 12 \\
\hline & & OT & 79 & 12 & 9 \\
\hline & & PT & 78 & 8 & 14 \\
\hline \multirow[t]{4}{*}{ vi } & \multirow[t]{4}{*}{ I would like more teaching online } & ASES & 23 & 17 & 60 \\
\hline & & DR & 12 & 4 & 84 \\
\hline & & OT & 12 & 3 & 85 \\
\hline & & PT & 10 & 20 & 69 \\
\hline \multirow[t]{4}{*}{ vii } & \multirow{4}{*}{$\begin{array}{l}\text { It was not useful having homework quizzes } \\
\text { for every topic }\end{array}$} & ASES & 19 & 13 & 68 \\
\hline & & DR & 12 & 0 & 88 \\
\hline & & OT & 24 & 6 & 71 \\
\hline & & $\mathrm{PT}$ & 8 & 21 & 74 \\
\hline \multirow[t]{4}{*}{ viii } & \multirow{4}{*}{$\begin{array}{l}\text { Homework quizzes helped students check } \\
\text { understanding and ongoing learning needs }\end{array}$} & ASES & 77 & 9 & 15 \\
\hline & & DR & 92 & 4 & 4 \\
\hline & & OT & 91 & 0 & 9 \\
\hline & & PT & 92 & 5 & 3 \\
\hline
\end{tabular}

Results are in \% 
The online system only enabled collection of data relating to student access of $\mathrm{HW}$ and ALA. Student interaction with the HW and ALA is shown in Figure 1. ASES student engagement is the lowest across the subject groups.

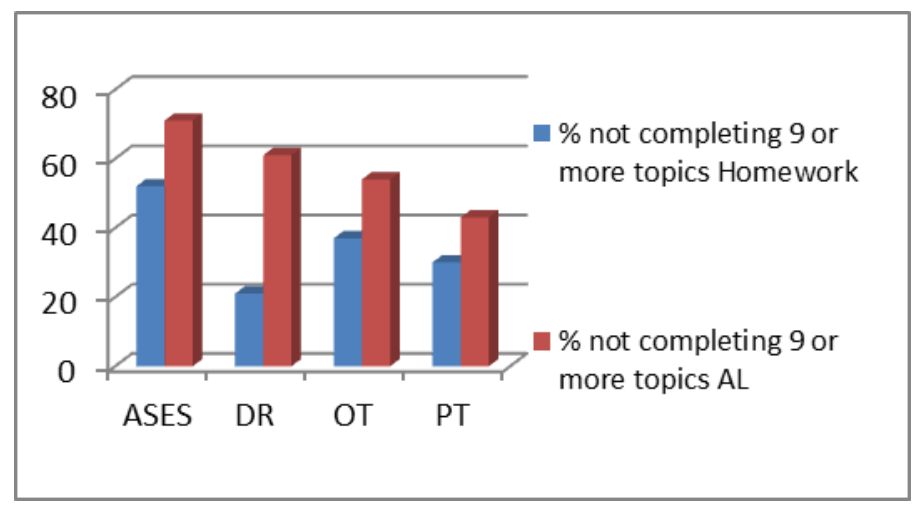

Figure 1. Engagement with homework and ALA by subject group.

All 155 students completed the summative assessment - a computer assisted multiple choice examination. Mean scores for the assessment from 2011/12, 2012/13 and $2013 / 14$ were $63 \%, 61 \%$ and $57 \%$ respectively with only scores for $2013 / 14$ showing a statistically significant drop $(12 / 13 p=0.0137,12 / 14 p=<0.00013 / 14 p=0.008)$.

Analysis by course (Figure 2) indicates that only the ASES results demonstrate a significant difference across the years with a reduction in mean score of $9 \%$ between $2012 / 13$ and $2013 / 14(p=<0.000)$. There was no significant difference in the other subject groups across the years (DR $p=0.614$, OT $p=0.673$ and $P T p=0.168$ respectively). Results of a comparison of workshop topics and those supported only by 'drop in' are shown in Table 4 and show no significant difference between methods $(p=0.882)$.

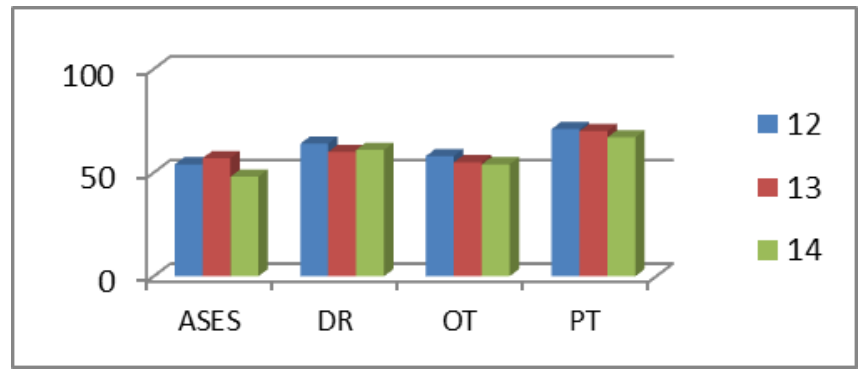

Figure 2. Comparison of scores by subject group. 
Table 4. Comparison of session type.

\begin{tabular}{|l|l|l|}
\hline & Mean (SD) & $\mathrm{p}$ \\
\hline Online & $55(21)$ & \multirow{2}{*}{0.882} \\
\cline { 1 - 2 } Workshop & $56(22)$ & \\
\hline Online ASES & $55(21)$ & 0.646 \\
\cline { 1 - 2 } Online DR/OT/PT & $55(21)$ & \\
\cline { 1 - 2 } Workshop ASES & $57(22)$ & \multirow{2}{*}{0.391} \\
\cline { 1 - 2 } Workshop DR/OT/PT & $57(22)$ & \\
\cline { 1 - 2 } & &
\end{tabular}

\section{Discussion}

Over $90 \%$ of DR, OT and PT students and $72 \%$ of ASES reported they understood why more independent learning methods were being used, and the majority of students in all subject groups reported they felt sufficient direction to self-study was provided. Despite this, however, more than $50 \%$ of PT, OT and ASES agreed it was more difficult to learn the online topics, although this dropped to $42 \%$ for DR. Additionally, $68 \%$ of OT students and $59 \%$ ASES agreed that it was difficult to get to grips with the independent learning style. Interestingly, however, the DR and PT students disagreed with this, indicating the majority of these student groups found it easy to adapt to the independent requirements.

Qualitative data suggests that a major challenge for students was a lack of motivation when there was no class. These findings concur with those of Wilson and Solheim (2008) who investigated promoting independent skill acquisition and found that students did not complete independent learning tasks unless a staff member was present. An interesting statement from one student was 'the lecturers don't want to spoon feed us but we want spoon fed'.

Andragogy, as indicated in Taylor and Laros (2014), suggests that adults are more selfdirected in their learning, more ready to learn, keen to apply learning, and have intrinsic motivation, all traits required for independent learning. However, the data presented here, and in Wilson and Solheim (2008), suggests that many first year students are not yet working within these principles and that the level of independence imposed during the $A$ \& $\mathrm{P}$ module was too much for many of the students. Since the majority of students in 
year 1 are only 17 or 18 years of age this should not be surprising: they have yet to gain a context for the material being learnt, or to perceive its relevance to their profession, and were not being required to apply it. Consequently they may lack the motivation to engage with the independent learning required.

Jezegou (2013) found that, even with adult learners, predetermined requirements were perceived positively as a motivator forcing them to work. Several studies have reported that undertaking formative online quizzes improves summative outcomes (Upton, 2005; Kibble, 2007; Coffee and Hillier, 2008). However, Kibble (2007) supports the 'predetermined requirement' of Jezegou (2013) by suggesting the improvement is most noticeable when engagement is enforced, for example, by attaching course credit. This suggests that undergraduate students require extrinsic motivation and may not be academically ready for the responsibility that this independent learning approach required. Workshops, an extrinsic motivator, may have acted to encourage students to undertake directed study (Box 1) as class activities would expose their level of preparedness while also providing reassurance relating to topic understanding. Noncompletion of quizzes and ALA accrued no penalty and completion no reward, therefore no motivation was provided.

In addition to motivation problems, confidence in learning was an issue; student comments indicated they found it easier to learn when staff reviewed topics with them (Box 1) as it gave them confidence in their learning. This concurs with Steele et al. (2002) who reported that students found the lecturer's ability to highlight key aspects, and emphasise important points, improved their confidence in their learning. Certainly workshop tasks were directed at ensuring students had grasped key areas of knowledge and clarifying misconceptions.

Other comments (Box 1) suggest that students may have felt overwhelmed by the quantity of knowledge required, with the variety of resources provided, and quantity of information contained within them, adding to this feeling. Steele et al. (2002) reported similar problems and Johnson et al. (2013) found that students did not have confidence to determine what constituted an appropriate learning resource.

Although the learning resources used here were pre-screened by staff, students may not have investigated the full variety of potential learning tools due to this lack of confidence. 
This is supported by the data presented in Table 1. This lack of exploration could lead to a self-perpetuating cycle, as Wen-Yu Lee and Tsai (2011) suggest that if students are not forced to use online resources they do not give themselves enough exposure to feel comfortable using them and, therefore, the resources will be less useful in self-regulated learning as students avoid using them. One session was provided to guide the students to the resources. However, further sessions, which include tasks to encourage students to find and explore the various different resources, may have helped encourage this exposure, and therefore confidence, in using the various resources.

Additionally, the 'what you need to know' sheets used in the module had very specific content that the students needed to know. This often omitted sections of a chapter in the core text. Most of the online resources were designed to address the whole book chapter, however, only the homework quizzes could be fully customised to our content. Consequently students had to navigate the online content independently to find the sections of resources relevant to them.

Although there are views in the literature indicating it is advantageous for students to have access to a wide range of information (Marc 2002, cited Al-Qahtani and Higgins, 2013) this is contradicted by Johnson et al. (2013) who found that students preferred resources that were directly focused on their module content. Johnson et al. (2013) indicate this enabled the students to be confident they were addressing the module learning requirement. It also meant they did not have to make independent judgements about the quality of a resource or waste time finding the relevant content. The lack of use of a wide range of available resources found here would suggest support for this view rather than that of Marc (2002, cited AI-Qahtani and Higgins, 2013). Consequently other online resources which had fewer learning tools, but which could be more selectively allocated to map to the module content, may have been more beneficial and future research should investigate this.

Lack of confidence in the online topics may also relate to the method of learning however. McNulty et al. (2012) demonstrated a positive correlation between constructive learning and course performance and a negative correlation when rote learning was used, indicating that students adjust their learning strategies depending on the tasks required of them. Similar findings were reported by Subramanian et al. (2012). 
Workshops encouraged a more active learning approach and encourage constructive learning, while ALA may encourage rote learning through memorising information. Interestingly, Galy et al. (2011) suggest that the perceived usefulness of resources, and ease of use, relate to final course grade. Although students perceived the homework quizzes and ALA to be most useful, their actual use of them did not mirror this perception, particularly in relation to ALA (Table 2 and Figure 1). This may link to irrelevant content (Johnson et al., 2013) as ALA could not be made entirely specific to the course syllabus, the time it could take to complete ALA activities, or simply to ease of access. Results shown in Table 3 suggest there may be a stronger link between summative achievement and completion of homework quizzes rather than ALA, since all subject groups had poor completion of ALA activities but DR and PT, the two strongest performing groups, had better homework completion. The benefit of homework quizzes is supported by Kibble (2007) and Wilson and Solheim (2008). However, a recent study by Griff and Matter (2013) questions the benefit of incorporating ALA as they found no difference in student achievement in those using ALA compared to those using simple online quizzes. A lack of randomisation to groups and huge variability in how ALA was used across different institutions does put some doubt on these findings, however, their findings are replicated in this case report.

If, as McNulty et al. (2012) suggest, constructive learning improves summative outcome in comparison to rote learning, this questions why scores in summative assessment topics did not differ between workshop and online topics. The answer may lie in the content of the module and its method of assessment, as the multiple choice assessment only required rote learning. The aim of using more constructive learning strategies was to facilitate greater retention of knowledge for subsequent years, something that was not measured in this project. The overall drop in student achievement for the 2013/14 cohort may be due to the cohort involved but this could only be established if the module were delivered in the same way for another year.

Interestingly, while over $80 \%$ of DR and OT students indicated they do not want more independent online learning, this dropped to $60 \%$ of ASES students and $69 \%$ of PT students. This is difficult to reconcile with the lack of engagement with the homework quizzes and ALA and the self-reported use of other resources. These percentages do, however, indicate that the majority of students do not want to increase the amount of online teaching. It may be possible that developing learning opportunities that engage the 
students with the basic A \& P more constructively, however, could allow an increased opportunity for teaching this aspect online. For example, if $A \& P$ were taught with pathology, the students would have to engage with the basic physiology or anatomy to be able to explain how pathology alters it. Classes could focus on this integration while online activities address the core knowledge base. This would be fitting with several other studies who found that adding e-learning resources to face-to-face teaching produced better summative achievements than replacing face to face teaching (Elizondo-Omana et al., 2004; Castilho-Weinert and Lopes, 2009; Al-Qahtani and Higgins, 2012). The likelihood is that this is due to an emphasis on constructive learning as advocated by McNulty et al. (2012).

It would have been interesting to have investigated in more depth why students found more independent learning more challenging. Analysis of this, in conjunction with the student's academic background, may have provided greater insights into the challenges students faced: also whether some groups of students may benefit more from this approach from the beginning while others require a more gentle introduction.

\section{Conclusion}

The results of this case study indicate that students found it challenging to move straight into independent learning, although it was not detrimental to their overall summative achievement. This may relate to lack of intrinsic motivation and/or lack of confidence. Students may also have failed to gain benefit from potentially engaging and useful independent learning tools due to the challenge of negotiating the resources and lack of confidence in using them. However, this data relates to only one cohort of students and cannot therefore be widely generalised.

Data also suggests that methods to encourage constructive learning and avoid rote learning are desirable. It may therefore be beneficial to investigate if students engage more with online learning of $A \& P$ using specific, but more limited, learning resources. Also if this, in addition to workshops that use this knowledge in relation to pathologies linked to their chosen profession, improves results. 
Motivation to complete online quizzes to focus A \& $P$ learning could be provided by allocating a proportion of the summative grade from quiz completion and linking it to the grade achieved on each task. This would provide extrinsic motivation while still encouraging the development of independent learning skills and providing reassurance relating to the learning achieved. Further research should investigate if this provides any benefit to student outcome.

\section{Acknowledgements}

Thanks to the Department of the Enhancement of Teaching Learning and Assessment for supporting this project with a teaching and learning development grant. I would also like to thank the Head of the School of Health Sciences for supporting the project by purchasing access to the online resources and the module team who helped pull the resources together for teaching.

\section{References}

Al-Qahtani, A.A.Y. and Higgins, S.E. (2013) 'Effects of traditional, blended and e-learning on student's achievement in higher education', Journal of Computer Assisted Learning, 29(3), pp. 220-234 [Online]. Available at:

http://onlinelibrary.wiley.com/doi/10.1111/j.1365-2729.2012.00490.x/epdf (Accessed: 24 February 2015).

Bligh, D. (2000) What's the use of lectures? San Francisco: Jossey-Bass Publishers. Available at:

http://isites.harvard.edu/fs/docs/icb.topic38998.files/Bligh Ch1 and Ch3.pdf (Accessed: 10 July 2015).

Bloomfield, J., Roberts, J., and While, A. (2010) 'The effect of computer assisted learning v's conventional teaching methods', International Journal of Nursing Studies, 47(3), pp. 287-94. 
Bunce, D.M., Flens, E.A. and Neiles, K.Y. (2010) 'How long can students pay attention in class: a study of student attention decline using clickers', Journal of Chemical Education, 87(12), pp. 1438-1443 [Online]. Available at:

http://pubs.acs.org/doi/pdf/10.1021/ed100409p (Accessed: 10 July 2015).

Castilho-Weinert, L.V. and Lopes, H.S. (2009) 'Computers in physical therapy education: interactive multimedia learning with MuStreT', Informatics in Education, 8(2), pp. 157-172 [Online]. Available at:

http://www.mii.lt/informatics in education/pdf/INFE149.pdf (Accessed: 10 July 2015).

Coffee, J. and Hillier, S. (2008) 'Teaching pre-cursor clinical skills using an on-line audiovisual tool: an evaluation using student responses', MERLOT Journal of Online Learning and Teaching, 4(4), pp. 469-476 [Online]. Available at: http://jolt.merlot.org/vol4no4/coffee 1208.htm (Accessed: 10 July 2015).

Cohen, L., Manion, L. and Morrison, K. (2000) Research methods in education. $5^{\text {th }}$ edn. London: Routledge and Falmer.

Elizondo-Omana, R.E., Morales-Gomez, J.A., Guzman, S.L., Hernandez, I.L., Ibarra, R.P. and Vilchez, F.C. (2004) 'Traditional teaching supported by computerassisted learning for macroscopic anatomy', The Anatomical Record (Part B: New Anatomy), 278B(1), pp. 18-22 [Online]. Available at:

http://onlinelibrary.wiley.com/doi/10.1002/ar.b.20019/pdf (Accessed: 10 July 2015).

European Community (2007) Key competencies for lifelong learning: a European reference framework. Available at: http://europa.eu/legislation summaries/education training youth/lifelong learning/ c11090 en.htm (Accessed: 28 February 2015).

Faleye, S. (2011) 'The CCAILM Learning Model: an instructional model for teaching and learning of engineering modules', US-China Education Review, A7, pp. 626-635. 
Freeman, S., Eddy, S.L., McDonough, M., Smith, M.K., Okoroafor, N., Jordt, H. and Wendworth, M.P. (2014) 'Active learning increases student performance in science, engineering and mathematics', Proceedings of the National Academy of Sciences of the United States of America, 111(23), pp. 8410-8415 [Online]. Available at: http://www.pnas.org/content/111/23/8410.full.pdf (Accessed: 10 July 2015).

Fry, H., Ketteridge, S. and Marshall, S. (2014) A handbook for teaching and learning in higher education: enhancing academic practice. Hoboken: Taylor and Francis.

Galy, E., Downe, C. and Johnson, J. (2011) 'The effect of using e-learning tolls in online and campus based classrooms on student performance', Journal of Information Technology Education, 10(1), pp. 209-230 [Online]. Available at: http://www.editlib.org/p/111519/ (Accessed: 10 July 2015).

General Medical Council (2012) Continuing professional development. Guidance for all doctors. London: GMC. Available at: http://www.gmcuk.org/Continuing professional development guidance for all doctors 1114.p df 56438625.pdf (Accessed: 10 July 2015).

Gopal, T., Herron S. and Mohn, R. (2010) 'Effect of an interactive web based instruction in the performance of undergraduate anatomy and physiology lab students', Computers and Education, 55(2), pp. 500-512 [Online]. Available at: http://www.sciencedirect.com/science/article/pii/S0360131510000473 (Accessed: 10 July 2015).

Griff, E.R. and Matter, S.F. (2013) 'Evaluation of an adaptive online learning system', British Journal of Educational Technology, 44(1) pp. 170-176 [Online]. Available at: http://onlinelibrary.wiley.com/doi/10.1111/j.1467-8535.2012.01300.x/full (Accessed: 10 July 2015).

Health and Care Professions Council (2011) Your guide to our standards for CPD. London: HCPC. Available at: http://www.hpcuk.org/assets/documents/10003B70Yourguidetoourstandardsofcontinuingprofessi onaldevelopment.pdf (Accessed: 10 July 2015). 
Hilbelink, A.J. (2009) 'A measure of the effectiveness of Incorporating 3D human anatomy into an online undergraduate laboratory', British Journal of Educational Technology, 40(4), pp. 664-672 [Online]. Available at:

http://onlinelibrary.wiley.com/doi/10.1111/j.1467-8535.2008.00886.x/epdf (Accessed: 10 July 2015).

Jezegou, A. (2013) 'The influence of the openness of an e-learning situation on adult students' self-regulation', International Review of Research in Open and Distance Learning, 14(3), pp. 182-201 [Online]. Available at:

http://www.irrodl.org/index.php/irrodl/article/view/1450/2525 (Accessed: 10 July 2015).

Johnson, I.P., Palmer, E., Burton, J. and Brockhouse, M. (2013) 'Online learning resources in anatomy: what do students think?', Clinical Anatomy, 26(5), pp. 556563.

Kibble, J. (2007) 'Use of unsupervised online quizzes as formative assessment in a medical physiology course: effects of incentives on student participation and performance', Advances in Physiology Education, 31(3), pp. 253-260 [Online]. Available at: http://advan.physiology.org/content/31/3/253 (Accessed: 10 July 2015).

Mayer, R.E. (2003) 'The promise of multimedia learning: using the same instructional design methods across different media', Learning and Instruction, 13(2), pp. 125139 [Online]. Available at:

http://www.sciencedirect.com/science/article/pii/S0959475202000166 (Accessed: 10 July 2015).

McNulty, J.A., Ensminger, D.C., Hoyt, A.E., Chandrasekhar, A.J., Gruener, G. and Espiritu, B. (2012) 'Study strategies are associated with performance in basic science courses in the medical curriculum', Journal of Education and Learning, 1(1), pp. 1-12. 
Nursing and Midwifery Council (2015) The Code. Professional standards of practice and behaviour for nurses and midwives. London: NMC. Available at: http://www.nmc.org.uk/globalassets/siteDocuments/NMC-Publications/revisednew-NMC-Code.pdf (Accessed: 10 July 2015).

Quality Assurance Agency ( No date) Students. Available at: www.qaa.ac.uk/partners/students (Accessed: 28 February 2015).

Raynor, M. and Iggulden, H. (2008) 'Online anatomy and physiology: piloting the use of an anatomy and physiology e-book-VLE hybrid in pre-registration and post qualifying nursing programmes at the University of Salford', Health Information and Libraries Journal, 25(2), pp. 98-105.

Scottish Credit and Qualifications Framework (No date) The framework. Available at: http://scaf.org.uk/the-framework/scaf-levels/ (Accessed: 28 February 2015).

Sparks, A.C. and Smith, B. (2014) Qualitative research methods in sport, exercise and health. Abingdon: Routledge.

Steele D.J., Palensky, J.E.J., Lynch, T.G., Lacy, N.L. and Duffy, S.W. (2002) 'Learning preferences, computer attitudes and student evaluation of computerised instruction', Medical Education, 36(3), pp. 225-232.

Subramanian, A., Timberlake, M., Mittakanti, H., Lara, M. and Brandt, M.L. (2012) 'Novel educational approach for medical students: improved retention rates using interactive medical software compared with traditional lecture based format', Journal of Surgical Education, 69(2), pp. 253-256 [Online]. Available at: http://www.sciencedirect.com/science/article/pii/S1931720411003588 (Accessed: 10 July 2015).

Taylor, E.W. and Laros, A. (2014) 'Researching the practice of fostering transformative learning: lessons learned from the study of andragogy', Journal of Transformative Education, 12(2), pp. 134-147. 
Upton, D. (2005) 'On-line learning in nutrition and dietetics: student performance and attitudes', The Internet Journal of Allied Health Sciences and Practice, 3(1), pp. 18 [Online]. Available at: http://ijahsp.nova.edu/articles/vol3num1/upton.pdf (Accessed: 10 July 2015).

Wen-Yu Lee, S. and Tsai, C.C. (2011) 'Student perceptions of collaboration, selfregulated learning and information seeking in the context of internet based learning and traditional learning', Computers in Human Behaviour, 27(2), pp. 905914 [Online]. Available at:

http://www.sciencedirect.com/science/article/pii/S0747563210003614 (Accessed: 10 July 2015).

Wilson, N. and Solheim, H. (2008) Promoting independent skill acquisition in practical allied health education. York: HEA. Available at: http://www.health.heacademy.ac.uk/lenses/mp/m10172.html (Accessed: 10 July 2015).

\section{Author details}

Fiona Roberts is a Senior Lecturer in the School of Health Sciences, Robert Gordon University, Aberdeen. After training as a physiotherapist Fiona decided to become involved in teaching physiotherapy instead. Her special interest areas are enhancing the teaching and learning experience, as well as key areas of respiratory physiotherapy practice. 